\title{
Australian university fights off research council's 'hijack' bid
}

Sydney. A bruising battle has broken out between the Australian National University (ANU) and the Australian Research Council (ARC) over who should control the university's research finance and agenda. ANU leaders are accusing the ARC, Australia's major national grant-giving body, of trying to 'hijack' some of their funds in order to reallocate them to other universities.

Celebrating its 50th anniversary this year, the ANU is unusual in coming under the direct responsibility of the federal government. All other universities operate under the responsibility of individual state parliaments (of which there are six), although for more than two decades their funding has come from federal government agencies.

Through the research and postgraduate focus of its Institute of Advanced Studies (IAS), the ANU, located in Canberra, has long prided itself as the flagship for basic research in Australia's higher education sector. But the expansion of the university system over the past 30 years has fuelled the ambitions of other universities to become equal players in competition for research support.

About 30 per cent of operating grants to the universities - now totalling A $\$ 4.6$ billion (US $\$ 3.6$ billion) annually — was intended to support research, while a parallel scheme for allocating grants to individuals and small groups expanded through what has become the ARC. The annual competition for these latter funds, which amount to A $\$ 350$ million this year, has become intense.

In contrast, the IAS has enjoyed special treatment. This is because it is financed directly by the government through a block grant, which is distributed among eight specialized schools dedicated to research and postgraduate training, in areas ranging from Earth sciences to medical research, as well as centres for astronomy, and resource and environment studies.

Staff of the IAS, who often enjoy high academic reputations both nationally and internationally, stoutly defend the value of being able to decide their own research agenda. But the major metropolitan universities have steadily built their research bases to such an extent that they feel they are now in a position to challenge the IAS's claim to special treatment through the ARC.

In order both to plan its next seven years of activity and to develop a defence against potential challenges, the ANU set up a wide-ranging external review of the IAS in 1994, with the ARC as a participant. The review committee was chaired by Keith
Boardman, a former chairman of the Commonwealth Scientific and Industrial Organisation, and involved visits by 70 independent researchers from Australia and overseas.

In a report presented last year, the joint committee commented favourably on the quality of the institute, based on a variety of performance indicators. The review recommended the continuation of block funding, as well as a modest budget increase of $A \$ 2$ million per annum. It also said that IAS should not be disrupted with another major review for seven years.

But the ARC, chaired by Max Brennan, a plasma physicist formerly of the University of Sydney, had already got its foot in the door. At the request of the previous Labor government, the council produced a separate report, which has just been released by the new government. The ARC wants to determine the block allocation to the IAS, which came to A $\$ 151$ million in 1995 , and says that this should not be increased.

At the same time, the ARC asks for its own funding from the government to be increased by $\mathrm{A} \$ 3.5$ million year to boost its programmes for special research initiatives and infrastructure, saying that the IAS should be allowed to compete with other universities for money from these pools.

The reaction has been fierce. The ANU claims that the research council would, in effect, control the research agenda of the IAS. The university council has asked John Howard, Australia's new Prime Minister, to ignore the ARC proposals and accept those of its own joint review.
Susan Serjeantson, Director of the IAS, describes the ARC's report, to which she says the ANU was not privy, as "an audacious grab for power and an increase in [the ARC's] resources". If its proposals are accepted, she says, the research council "would control research in the higher education system almost absolutely".

The Australian Vice-Chancellors' Committee is staying outside the ANU/ARC fight, characterizing it "as purely an institutional affair". Indeed, leaders of other universities have been silent on the ANU's position, which is blurred by its membership of the newly resurgent 'Group of Eight' major metropolitan universities claiming pre-eminence in research.

The group appears to have broken ranks with the 28 other universities by meeting with Amanda Vanstone, the education minister, and publicly pressing for the diversification of higher education into predominantly research or teaching universities. It is lobbying for protection from feared cuts of up to $\mathrm{A} \$ 550$ million in operating grants, and has proposed raising revenue through advance fees for courses, and increasing students' deferred contributions.

Brennan describes the ANU's reactions as "revealing paranoia within the institute", and denies that the ARC is just a rubber stamp. "Nothing in our report substantiates the claim of a takeover of the IAS agenda," he says "Our report recognises the unique place of the IAS in the Australian university system, and makes constructive recommendations to enhance this role." Peter Pockley

\section{Now crop circles weave a double helix}

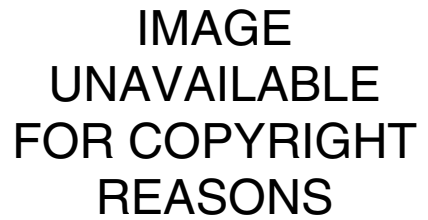

London. A mysterious double-helix pattern (above), 200 metres long, appeared overnight in a field of wheat last week near the English village of Alton Barnes in Wiltshire. The pattern, which contains 89 circles, was formed in under four hours, says Polly Carson, who owns the field. "There was nothing there at midnight," she says. "The next time we looked, at 4 a.m., it was daylight, and there it was."

Carson says crop circles regularly appear in her fields, and she does not believe they are all hoaxes, as is frequently claimed. "Some are truly amazing," she adds. "We had a scale map of the Solar System. Everything in it was accurate, even the eccentricity of the planetary orbits and their distance from the Sun."
E. M. 